\title{
L La libertad en el horizonte de la filosofía de la acción ${ }^{1}$
}

\author{
Carlos Beorlegui \\ Universidad de Deusto
}

Resumen. En el estudio de la libertad y de las demás características de la mente humana han convergido dos estrategias diferentes: la de primera persona, basada en la introspección subjetiva, y la de tercera persona, centrada en la observación externa de la conducta. La primera es la que ha seguido tradicionalmente la filosofía, especialmente desde Descartes. La segunda es la defendida por el conductismo y muchas de las posturas dentro de la denominada filosofía de la mente. El déficit de esas dos estrategias extremas contrapuestas consiste en no poder mostrar ninguna de ellas una visión unitaria sino parcelada del ser humano. Este trabajo propone un modo de superar estas deficiencias que consiste en atender al estudio de la acción humana advirtiendo su peculiar estructura y significado, pudiéndose desde su estudio acometer también varias aproximaciones complementarias.

\begin{abstract}
In the study of freedom and other features of the human mind, two different strategies have converged: the strategy of the first person, based on subjective introspection and that of the third person, focused in the external observation of behavior. The first has been followed by Philosophy, especially after Descartes. The second is that defended by behaviorism and by many of the proponents of the so called Philsophy of Mind. The defict of this two extreme and opposed strategies consists in not being able to demonstrate an unified visión but a fragmented one of the human being. This work propposes a way to overcome these defficiencies that consists in focusing of the study of human action, taking into account its peculiar structure and meaning. This study can be undertaken from many complementary approaches.
\end{abstract}

Palabras claves: Libertad, filosofía, antropología, mente, ética, conducta humana

Keywords: Freedom, philosophy, anthropology, ethics, mind, human behaviour 


\section{Introducción}

En el estudio de la libertad y de las demás características de la mente humana han convergido durante mucho tiempo dos estrategias diferentes, contrapuestas y en muchos momentos irreconciliables: la de primera persona, basada en la introspección subjetiva, y la de tercera persona, centrada en la observación externa de la conducta. La primera es la que ha seguido tradicionalmente la filosofía, especialmente desde Descartes. La segunda es la defendida por el conductismo y muchas de las posturas dentro de la denominada filosofía de la mente (Gardner, 1987).

El déficit de esas dos estrategias extremas contrapuestas consiste en no poder mostrar ninguna de ellas una visión unitaria sino parcelada del ser humano. La estrategia de primera persona tiene como ventaja atender a la experiencia interna, irrenunciable, de cada sujeto, aunque puedan darse errores y en peligro de descubrir nuestros propios engaños, pensando que somos libres sin serlo (Rubia, 2007). Además, desde la estrategia de primera persona no se puede mostrar una visión de la mente que tenga consistencia intersubjetiva, aparte de que, en muchos casos, se aliaba esta estrategia con una concepción dualista del hombre. Esta búsqueda de evidencias objetivas e interpersonales es lo que empujó al estudio de la mente desde la óptica de la tercera persona. Pero la limitación de esta estrategia está en que nunca llega a dar cuenta de las experiencias internas de cada sujeto (los famosos qualia), convirtiendo un aceptable reduccionismo metodológico en otro ontológico y antropológico, reduciendo al ser humano a su materialidad corpórea, y explicando su conducta como una mera sucesión de relaciones causales entre los estímulos externos y las respuestas biológicas del organismo, desconociendo la trascendental diferencia entre conducta y acción. La primera se mueve dentro de una cadena de relaciones causales, mientras que la segunda atiende a la intencionalidad y al cúmulo de significados que todo comportamiento humano posee.

Un modo de superar estas deficiencias consiste en atender al estudio de la acción humana, advirtiendo su peculiar estructura y significado, pudiéndose desde su estudio acometer también varios estudios complementarios:

- La comparación entre la conducta de los animales y la de los humanos, entendiendo que nuestra conducta surge dentro del proceso evolutivo, dándose respecto a él una continuidad a la vez que una ruptura; 
- y una visión unitaria de lo humano, en la medida en que la acción pretende acometer unitariamente la vertiente mental e intencional y la vertiente física y corpórea de lo humano, no como dos cosas distintas y desvinculadas que se dan más o menos unidas, paralelas y acompasadas, sino como una estructura única, dotada de doble vertiente: la física y la mental.

Para verlo de forma ordenada, lo primero que tenemos que hacer es advertir los rasgos específicos de la acción humana de la mano de los teóricos más significativos de la filosofía de la acción, para después situar comparativamente la acción humana dentro de las conductas animales, advirtiendo lo que tienen de continuidad y de diferencia; y a continuación, como último paso, situar la libertad dentro de la estructura específica y peculiar de la acción humana.

\section{La estructura de la acción humana}

Como ya lo hemos dicho, tanto en el estudio de la libertad como en el más amplio de la filosofía de la mente, las discusiones se han centrado en situar el problema en el ámbito de la intuición subjetiva, en donde la libertad se reducía a una experiencia personal e incomunicable, o bien, dejarlo al estudio de la conducta externa donde se tendía a negar la libertad, puesto que no es un elemento que aparece ni se da en el horizonte de las meras relaciones causales entre estímulorespuesta, por más que se pueda complejizar la estructura conductual con reflejos condicionados y la teoría del refuerzo de Skinner, puesto que la libertad no aparece nunca en el mero análisis externo de la conducta.

Un modo de solventar y superar estas dificultades consiste en advertir que el comportamiento humano, donde se sitúa la libertad, no está constituido por la conducta sino por la acción. Se necesitaba, por tanto, desarrollar una teoría o filosofía de la acción para dar cuenta certeramente del modo cómo hay que entender el comportamiento humano y cómo desarrollan sus estrategias frente al medio ambiental y ante los demás componentes de su especie.

Los diversos filósofos que han dedicado sus esfuerzos al análisis de la acción ${ }^{2}$ coinciden en sus elementos esenciales, pero difieren en muchos de sus aspectos complementarios. Las acciones humanas son sucesos que se desarrollan en el mundo, produciendo en él diversos efectos y consecuencias. Pero se trata de un tipo de sucesos especiales, puesto que hacen referencia a un agente, y poseen dos caras o facetas: una dimensión 
física, nivel de interconexión con las realidades físicas del mundo, y una dimensión intencional, ámbito de las decisiones de los agentes que las producen. Por tanto, las acciones se sitúan en medio, o son una síntesis, ya que abarcan tanto los actos mentales como los sucesos físicos. Los actos mentales o pensamientos no suponen cambios somáticos, mientras que los actos físicos no implican la intervención de un agente intencional que persigue un fin determinado con esos cambios físicos.

Por todo esto, los diversos autores que estudian las características esenciales de las acciones humanas nos hacen ver la complejidad de las mismas y la pluralidad de rasgos que las constituyen. ${ }^{3}$ Visto desde el punto de vista del agente, una acción supone siempre un objetivo intencional, como ya se ha señalado. Pero también es importante tener en cuenta la situación - las circunstancias en las que se desarrolla la acción, hallándose en este aspecto la problemática sobre las limitaciones o dificultades de la libertad en el momento de realizar una determinada acción, pero la circunstancia más específica de una acción se halla en su dimensión interpersonal y social, en la medida en que las acciones hacen referencia a unas reglas, de tal modo que solamente podrá entender la acción quien conozca tales reglas, el que domine los significados del juego social en el que se sitúa cada acción, puesto que las reglas son creación social, reglas de juego para organizar con sentido las interrelaciones entre los diversos seres humanos. ${ }^{4}$

Por tanto, explicar una acción es entenderla como un modo de comportarse de un agente frente a otros, siguiendo en una determinada circunstancia las reglas de conducta correspondientes a un conjunto social en el que se sitúa un actor o agente. La intencionalidad es el elemento esencial que define $y$ distingue a las acciones, exigiendo dentro de sí el deseo o la decisión de lograr algo realizando una acción determinada, y aunque el agente no consiga aquello que persigue con su acción, ésta no deja de ser intencional. Ahora bien, la intención es solamente el punto de partida, aunque no el punto final de la acción, puesto que, como ya hemos señalado, hay que tener en cuenta dentro de la acción la situación mundana y el entorno social de los otros agentes.

Todo esto guarda relación con lo que G. H. von Wright denomina "trasfondo motivacional", es decir, "la existencia de una acción supone (junto a las razones) la actividad física que la haga posible, la oportunidad (un estado de cosas que la haga posible) y la capacidad del sujeto para realizarla" (Gómez, 2002, p. 9-50, 18). Y dentro de esa capacidad, von Wright distingue entre la capacidad genérica y la concreta, siendo la primera la 
capacidad de actuar que poseen todos los agentes humanos como comer, andar, trabajar, entre otros., mientras que la capacidad concreta es la acción de comer, andar o trabajar realizada por un agente concreto. Pero las acciones humanas no adquieren su sentido completo más que situándola en una "historia" acerca del agente y en el contexto completo de su historia (Von Wright, 1980, p. 192).

Eso es lo que implica que explicar una acción no pueda situarse en el mismo nivel que explicar un suceso físico. Explicar una acción supone, para von Wright, responder a la pregunta de por qué se ha realizado. Se trata, por tanto, de relacionar correctamente la intención con la acción, puesto que esa relación no es causal, al estilo de la causalidad física, sino que se trata de comprender las razones que el agente ha tenido para actuar de un modo determinado. Así, el motivo o la razón de una acción no es igual que su causa. Pero "esto no significa que la acción intencional esté al margen de la causalidad, sino que los factores causales tienen un papel secundario en su explicación" (Gómez, 2002, p. 20).

La explicación de la acción separa el aspecto de la naturaleza (dominado por la causalidad) de la dimensión del significado (intencionalidad). Pero no se trata de dar una doble explicación de una misma acción, sino de advertir la doble cara de un mismo acontecimiento. Por tanto, "la acción, en tanto que movimiento corporal, es un único acontecimiento objeto de una doble descripción, como acción intencional y como conducta meramente corporal" (Gómez, 2002, p. 21). Así, el lado intencional no se reduce a lo físico, ni la faceta física es suficiente para explicar la intencionalidad.

En definitiva, para von Wright, el concepto de causa, utilizado en el ámbito de las relaciones entre objetos físicos, no sólo no es suficiente para explicar las acciones humanas, sino que es precisamente deudor de la experiencia que tenemos en la realización de nuestros actos conductuales. De ahí que tenga razón Hume cuando niega que tengamos conocimiento directo de la relación causal entre realidades físicas. Lo que ocurre es que, desde la experiencia que tenemos de la relación existente en nuestras acciones entre razones y resultados, lo proyectamos sobre la relación causa-efecto en el mundo físico. De tal modo que llegamos a la comprensión de esta relación a partir de la observación de nuestros actos intencionales. Por tanto:

"aunque las relaciones causales existan en la realidad independientemente de los agentes (tesis ontológica), su conocimiento se da a través de la intervención activa de los humanos y, en 
consecuencia, la causalidad es epistémicamente dependiente de la acción aunque no lo sea ontológicamente" (Gómez, 2002, p. 23).

Searle no coincide del todo con esta apreciación, puesto que considera, a diferencia de von Wright, que llegamos al conocimiento de las relaciones causales no tanto a través de las acciones, sino en el ejercicio mismo de su realización. La dificultad de la tesis de von Wright está en que no se podría explicar cómo la observación de la acción nos aporta un conocimiento de la relación causal física (Gómez, 2002, p. 24).

Las tesis sobre la acción de J. Searle y de G. H. von Wright coinciden, en sus líneas generales, al mismo tiempo que sus planteamientos se complementan. Searle, dentro de la común diferenciación que se da en toda acción entre la dimensión intencional y la física, distingue entre intención previa e intención en acción (Searle, 1983). La intención previa se expresa con "haré A", o "voy a hacer A", mientras que la intención en acción se expresa con "estoy haciendo A". Es decir, la intención previa es la representación mental de lo que el agente quiere llevar a cabo, mientras que la intención en acción es la representación que posee el agente mientras está realizando esa acción. Dicho de otra forma, "la intención previa representa toda la acción como soporte de sus condiciones de satisfacción; mientras que la intención en acción presenta (no representa) el movimiento físico como soporte de sus condiciones de satisfacción" (Zunzunegui, 1992, pp. 989-1003, 995).

Searle contempla también otro tipo de acciones, como acciones sin movimiento corporal (cuando la intención positiva consiste en no hacer ningún movimiento); acciones negativas (no hacer algo como condición para realizar una intención); actos mentales (sucesos exclusivamente mentales); y acciones no-intencionales (son acciones que acompañan inconscientemente a una acción consciente, como efecto secundario o no previsto, por ejemplo: casarse con una persona, sin saber que posee otra identidad) (Zunzunegui, 1992, p. 995).

Por otro lado, Searle también distingue en las acciones entre intención individual y colectiva. La diferencia es evidente, pero es interesante distinguirlas, porque hay veces en que se dan diversas intenciones individuales simultáneas o cercanas, sin que se dé una intención colectiva, es el caso de la reacción de un grupo de personas sentadas en un prado al ponerse a cubierto cuando empieza a llover. Se trata de un conjunto de intenciones individuales similares y simultáneas, pero que no forman 
una intención colectiva. Para que se dé ésta, se necesita que el conjunto de las acciones individuales estén relacionadas y conjuntadas desde un propósito colectivo que las unifica y les da sentido. Es el caso, por ejemplo, en que ese mismo colectivo de personas fuera un grupo de actores que están interviniendo en la filmación de una película, y estuvieran respondiendo sus acciones a un guión cinematográfico en el que se ordena que cuando empiece a llover tienen que levantarse $y$ marcharse.

Ambas acciones no pueden ser distinguidas por quien no esté al tanto del plan inscrito en el guión cinematográfico, de tal forma que la descripción física de ambos hechos es la misma, pero el significado de ambas acciones es muy diferente. La relación entre la intención individual dentro de la colectiva es la de un medio para conseguir un fin (el plan o intención colectiva). Pero no se da entre ambas intenciones una relación causal, esto es; el acto colectivo no causa el acto individual, sino que éste forma parte de aquél.

Como indica E. Zunzunegui (1992, p. 996), esta descripción de las acciones realizada por Searle se refiere a su realidad ontológica y a su origen mental, mientras que $\mathrm{G}$. $\mathrm{H}$. von Wright (1970) se refiere más bien a la descripción del funcionamiento de una acción, esto es; a la lógica del cambio o a la lógica de la acción. Dentro de esta lógica, von Wright distingue entre suceso y proceso. En un suceso se da un cambio de estado de cosas a otro, habiendo una diferencia de estados o situaciones mundanas, requiriéndose una sucesión temporal, de tal modo que para pasar de un estado inicial a otro final se requiere una acción humana. Proceso es una serie de sucesos continuos en un período de tiempo en el que no se distinguen los momentos intermedios.

Esta distinción es fundamental para situar y distinguir los cuatro conceptos básicos de la teoría de la acción de von Wright: actividad, acción, acto y abstención. Actos y abstenciones son dos modos o tipos de acción. Los actos, aunque están relacionados con los sucesos, no son un tipo de sucesos, puesto que un acto no es un cambio en el mundo, aunque sí lo provocan y causan. Así que tenemos que diferenciar entre acto y actividad: "Cerrar una ventana o matar a una persona es ejecutar un acto. Fumar o correr o leer es estar ocupado en una actividad" (Von Wright, 1970, p. 58). ${ }^{5}$ Por tanto:

De la misma manera que los actos están relacionados con los sucesos, así las actividades están relacionadas con los procesos (...). Los sucesos acaecen, los procesos avanzan. Los actos efectúan el acaecer de los sucesos; las actividades mantienen los procesos en marcha. (Von Wright, 1970, p. 58) 
En definitiva, el acto tiene siempre un resultado (el cambio de estado en el mundo) y puede tener una consecuencia (ese cambio, ocurrido por una causa natural), es el caso de abrir una ventana. Pero la actividad no tiene resultado, aunque sí puede tener consecuencias. Las abstenciones son la cara negativa de los actos, de tal modo que se trata de actos en los que se supone que un agente puede hacer algo, pero ha decidido no hacerlo (Von Wright, 1970, p. 62) y (Zunzunegui, 1992, p. 997).

Por tanto, mientras Searle se centra en la dimensión ontológica de la acción y en su origen, von Wright se detiene más bien en la práctica de las acciones, sean positivas o abstenciones. Lo que vamos a tratar a continuación es ver cómo entienden ambos autores el hecho de la libertad dentro de esta teoría de la acción. Las acciones humanas son conductas que inciden en el ámbito físico, por tanto, tienen una dimensión observable para cualquiera, ateniéndose en ese ámbito a la relación de causa-efecto, pero poseen también una dimensión de libertad en el aspecto intencional.

Esa dimensión es la que los diferencia de las acciones animales. Por eso, antes de centrarnos en estudiar la libertad como elemento de las acciones humanas, nos vamos a detener en la comparación y la relación entre las acciones humanas y las animales, entendiendo que las acciones animales son el anticipo evolutivo de la conducta humana, siendo de gran utilidad advertir en la comparación entre acciones animales y humanas lo que tienen de continuidad y parecido, al mismo tiempo que de ruptura y diferencia.

\section{De la conducta animal a la acción humana}

La teoría evolucionista nos ha mostrado que la especie humana es el resultado de un largo proceso evolutivo desde el que ha emergido. Por tanto, las peculiaridades de nuestra especie se hallan apuntadas y preanunciadas en las especies anteriores, produciéndose un proceso preparatorio que se inicia con mucha antelación en especies anteriores y que termina en los humanos. Esto se puede decir de todo o de casi todo lo que caracteriza a los humanos $\mathrm{y}$, por tanto, también de la mente consciente y de la volición libre. Vamos a detenernos en este apartado en reflexionar sobre el proceso evolutivo de la mente y de la volición humana, advirtiendo la continuidad con el proceso evolutivo, así como sus diferencias y rupturas.

Como todo proceso continuado, resulta difícil situar con precisión las rupturas y saltos emergentes, tendiendo a presentarse siempre dos posturas: la que insiste en la 
continuidad y la que lo hace en la ruptura, considerando por nuestra parte que resulta más productivo y acertado situarse en una postura intermedia sintética. Aunque hay que precisarla con datos concretos.

El etólogo K. Lorenz (1980) en La otra cara del espejo, adhiriéndose a la teoría de la selección natural de Darwin, nos muestra cómo cada una de las especies es el resultado de un lento pero exitoso proceso de adaptación al medio, siendo cada ser vivo una estructura capaz de captar del entorno los datos necesarios para adaptarse inteligentemente al mismo, sobrevivir y dejar una descendencia dotada de similares capacidades de adaptación. El proceso evolutivo sería, por tanto, un inteligente y continuado proceso en el que, a través de sucesivas mutaciones genéticas, se van generando seres vivos cada vez más complejos, que poseen unas mayores capacidades de captar mensajes del medio y de responder adecuadamente a los mismos, produciéndose como un diálogo inteligente entre el ente vivo y su entorno ecológico que avanza y progresa en espiral. Sólo las especies animales, y cada uno de sus componentes individuales, que han sido dotados de estos mecanismos de adaptación y de respuesta a su nicho ecológico, han sobrevivido y dejado descendencia.

La cuestión a plantear, en relación al tema que nos ocupa, es si podemos afirmar, dentro de este proceso adaptativo animal, que todos los seres vivos tienen mentes, esto es, si están dotados de un sistema cognitivo y volitivo que sea capaz de recibir datos del entorno y de responder de forma adecuada, esto es, inteligente a sus necesidades de supervivencia. ${ }^{6}$ Tras el recorrido que los expertos hacen de los rasgos comportamentales de las diferentes especies vivas, desde los protozoos hasta los humanos, y distinguiendo entre las diferentes teorías que se presentan al respecto sobre qué entendemos por mente y por cognición, podemos concluir que resulta más adecuado, frente a las posturas que consideran que todo procesamiento de información por parte de los seres vivos hay que considerarlo como cognición, restringir dicho concepto a conductas más complejas. Hay que distinguir, por tanto, entre procesos en los que se da un intercambio de sustancias químicas entre el ser vivo y el medio, y los intercambios en los que se da también algún tipo de representación. La representación es un elemento mediador entre el ser vivo y el medio, entendiendo que:

Las representaciones han de ser semánticamente evaluables, es decir, deben poder ser verdaderas o falsas, correctas o incorrectas, con respecto a la situación de la que se suponen que son una representación. Dicho de otro modo, para que haya 
auténticas representaciones debe darse la posibilidad de una mala representación (misrepresentation). (Diéguez, 2009, p. 211)

Igualmente, para que haya representaciones tienen que existir patrones de activación neuronal, como sustratos físicos de las mismas. Así, para atribuir cognición a un ser vivo tiene que poseer un sistema nervioso suficientemente complejo. En consecuencia, "la identificación de la vida con la cognición o la interpretación de la evolución como un proceso cognitivo no lleva más que a la dilatación del término cognición hasta hacerlo inútil desde un punto de vista explicativo" (Diéguez, 2009, p. 219).

Ahora bien, una vez distinguida la relación no cognitiva entre un ser vivo y su ambiente de la que sí se puede considerar como una relación cognitiva, también dentro de la cognición se dan niveles y diferencias, puesto que se dan cogniciones no conscientes y cogniciones conscientes como son las de los humanos. Hay autores que consideran que para que se dé una auténtica cognición, dotada de representaciones, tiene que poseer también la consciencia, es decir, experiencia subjetiva. ${ }^{7}$ Parece que la mayoría de los autores se inclinan a separar la cognición consciente, propia de los humanos, de la cognición no consciente, propia de los animales dotados de un elemental sistema nervioso. Lo propio de un proceso cognitivo sería poseer, por parte del animal, no sólo la capacidad de corregir su conducta en función de los datos que recibe del entorno, sino "ser capaz además de detectar los errores de sus inputs sensoriales y de volver a hacerlos coherentes usando toda la información de forma sistemática y corrigiendo o recalibrando la recepción de la parte de esa información que lo necesite" (Diéguez, 2009, pp. 214-215). En la medida en que un animal es capaz de ello, no sólo consigue responder a las condiciones del entorno que está delante, sino que es capaz de tener un mundo representado enfrente de sí.

La etapa última en el desarrollo evolutivo de la mente y de su capacidad cognitiva consiste en tener capacidad de poseer representaciones mentales de las propias representaciones mentales, esto es, tener representaciones conscientes o de segundo orden. Esto es una cualidad propia de la mente humana, y se discute si la poseen también algunos animales superiores como los chimpancés. Esta discusión lleva tiempo planteándose, sobre todo a partir de las investigaciones de Premack y Woodruff, y otros estudiosos de los comportamientos de los grandes simios. ${ }^{8}$ Se trata de dilucidar si los primates poseen lo que se ha denominado: teoría de la mente, esto es, la capacidad de atribuir a otros seres vivos estados mentales, 
creencias y deseos, y ponerse en el lugar del otro, leer las mentes de otros individuos. ${ }^{9}$ Esto es fundamental en el comportamiento de los seres humanos, en la medida en que te permite anticiparte al otro, influir en su conducta, y actuar de acuerdo a lo que prevés que va a ser la conducta del otro. Como puede suponerse, esta capacidad mental concede una gran ventaja adaptativa, puesto que en el ámbito de los humanos el entorno ambiental donde se desarrolla fundamentalmente la vida, con todas sus ventajas y peligros, no es tanto el entorno natural sino en ámbito interpersonal y social.

Hay estudiosos de los comportamientos de los primates que atribuyen sin ninguna duda teoría de la mente a los chimpancés, ${ }^{10}$ otros en cambio, lo dudan o lo niegan abiertamente, considerando que sólo la poseen los humanos, y hay otros que se mantienen en la duda al respecto desde una postura prudente. Para dilucidar esta cuestión, no basta con las posturas aprióricas, sino que tienen que aportarse pruebas empíricas, y éstas hay que reconocer que suelen ser en gran medida ambiguas, admitiendo todas las interpretaciones y conclusiones posibles.

Determinadas pruebas empíricas parece que permiten concluir que algunos chimpancés son capaces de representarse creencias, planes y deseos de otros chimpancés, y en algunos casos, han sido capaces de engañar a otros chimpancés. ${ }^{11}$ Ahora bien, en situaciones similares parece más bien dudoso que los chimpancés puedan interpretar las mentes de sus congéneres. Hay casos en los que se ve claramente que los chimpancés son capaces de entender que otro chimpancé desconozca algo que él conoce, pero no es capaz de entender que el otro chimpancé crea algo falso. Es decir, tienen capacidad para interpretar lo que otro chimpancé conoce o no sobre un dato de la realidad, pero no es capaz de entender una creencia de otro chimpancé sobre un dato que no corresponde a la realidad. ${ }^{12}$ Este dato es fundamental para decidir si los chimpancés tienen o no teoría de la mente, porque, como dice A. Diéguez (2009), "sólo en el caso de poder atribuir creencias falsas a otros individuos tenemos una prueba clara de que se comprende que el otro tiene estados mentales distintos de la situación real en el mundo" (p. 218).

Aun así, parece haberse dado alguna situación en experimentos similares con chimpancés en que algunos de ellos desarrollaban conductas en que igualaban la capacidad de captar mentes ajenas, similar a la capacidad de niños entre 4 y 5 años (O'Connell, y Dunbar, 2003, pp. 131-140). En un caso similar, se ha visto que una orangutana era capaz de reconocer una creencia falsa de sus cuidadores (Gómez, 2005, pp. 147-169). 
De todas formas, a pesar de estas presuntas evidencias empíricas, todas ellas pueden interpretarse desde claves no mentalistas, o ponerse en cuestión la metodología empleada en esas investigaciones. Por ello, no parece que se puedan sacar conclusiones contundentes a favor o en contra de ninguna de las posturas. Incluso, algunos autores pasan de unas posturas a otras, o se sitúan en posturas intermedias, como es el caso de Call y Tomasello (2008, pp. 187-192, 191), cuando concluyen:

En un sentido amplio de la frase "teoría de la mente", la pregunta a la fructífera pregunta que Premack y Woodurff hicieron hace treinta años es definitivamente sí, los chimpancés tienen una teoría de la mente. Pero los chimpancés posiblemente no entienden a los otros en términos de una psicología de creencias-deseos al estilo humano en la cual aprecien que otros tienen representaciones mentales sobre el mundo que dirigen sus acciones incluso cuando éstas no se corresponden con la realidad. Y, por tanto, en un sentido más estricto de teoría de la mente en tanto que comprensión de las creencias falsas, la respuesta a Premack y Woodurff podría ser no, no la tienen..$^{13}$

Ahora tenemos que dar un paso más, y pasar de la teoría de la mente a la capacidad de realizar voliciones libres. ¿Pueden hacerlo los animales? ¿Cómo se sitúa en el proceso evolutivo esta capacidad humana, en el esquema de continuidad y ruptura en el que hemos situado la capacidad mental? No cabe duda de que la volición es uno de los rasgos específicos de la conducta humana, en la medida en que "la volición se suele entender como un tipo de proceso por el cual el agente opera de manera racional, libre y consciente". ${ }^{14}$ Al igual que hemos hecho con el problema de la mente, en su sentido amplio, vamos a preguntarnos también si existe en el mundo animal algún rastro o presencia de una volición pre-humana.
Algunos estudiosos del cerebro, como Edelman, ${ }^{15}$ distinguen entre una consciencia primaria (volición elemental) y una consciencia secundaria o de segundo nivel. La volición de primer nivel la tendrían también los animales. Pero con ello no estamos sólo entrando de nuevo en la distinción de los humanos respecto a los animales, sino que el estudio de los mecanismos que poseen los animales a la hora de sus actuaciones nos pueden iluminar y ayudar a comprender los mecanismos de las acciones humanas y de la libertad. Con ello vamos a seguir comprobando cómo en el tema de la volición libre, al igual que en otros muchos aspectos de la condición humana, se da una continuidad con el mundo de la biosfera, al mismo tiempo que una ruptura y diferencia específica. 
Como siempre, necesitamos primero delimitar los conceptos que vamos a emplear, empezando por el de volición. La volición es un tipo de acciones generadas por un agente. Ya sabemos que, dentro de las reflexiones de la nueva filosofía de la mente, se discute si hay que considerar comportamientos inteligentes a los realizados por máquinas y por los animales. Toda acción inteligente estaría dotada por una intencionalidad y, por tanto, en ese caso se daría un agente susceptible de realizar auténticas voliciones. Aunque hay autores que tienen una concepción tan amplia de agente, que puede aplicarse al ámbito de la Inteligencia Artificial [Agentes son sistemas que pueden iniciar, sostener y mantener un continuo proceso de interacciones con su entorno como parte esencial de su funcionamiento normal: T. Smithers (1997, pp. 88-106), un agente es un sistema que trata de cumplir un conjunto de objetivos en un entorno complejo y dinámico: P. Maes (1994, pp. 135-162)], entendemos que esos supuestos objetivos que persiguen las máquinas inteligentes no son objetivos de las máquinas sino de sus diseñadores, viniendo a ser una prolongación artificial de ellos.

De ahí que para que un agente pueda ser considerado como tal, parece necesario entender que se trata de sistemas "cuya organización es capaz de automantenerse modificando activamente su entorno inmediato" (Moreno, 2009, p. 227). Es lo propio de los sistemas autónomos, y los robots no lo son, mientras que sí lo son los seres vivos. Así, un agente es un sistema autónomo, y sus movimientos son acciones encaminadas al automantenimiento del sistema autónomo. Eso puede hacerlo ya una bacteria en sus diferentes movimientos de interacción con su ambiente, encaminados a intercambiar con él diversos productos químicos para asegurar el mantenimiento de su organización metabólica. En esta relación entre el protozoo y su entorno, vemos que sus acciones están orientadas por el propio mecanismo sistémico con el que está construido. De ahí que lo que hace es lo que "debe" hacer para poder seguir viviendo y no descomponerse el sistema metabólico.

Según esto, todos los seres vivos son agentes autónomos, pero eso no significa que todas sus acciones sean de tipo volitivo, puesto que ya hemos dicho que para que haya volición tiene que darse en las acciones un cierto autocontrol consciente. De ahí que sea importante seguir el proceso evolutivo de los seres vivos para ver cuándo se daría la emergencia de los actos volitivos. Ya hemos hecho referencia, al hablar de la evolución de la teoría de la mente, al hecho de que el paso fundamental para la emergencia de los actos cognitivos necesita la aparición y desarrollo del sistema nervioso. El sistema nervioso dota al animal de la capacidad de mayor 
control sobre el ambiente y sobre sí mismo. La historia de la complejificación del sistema nervioso central y del cerebro nos indica que se da en ese proceso tanto un aumento del número de neuronas como, sobre todo, una progresiva y complicada sistematización de las mismas. ${ }^{16}$ Así, estructuras cerebrales de neuronas que en un momento inicial de su historia sirvieron para regular funciones automáticas como la respiración, la visión, los latidos del corazón, entre otras, quedan subordinadas en fases posteriores de complejidad, y reorganizadas bajo la orientación de funciones más complejas del cerebro. Por ello, un elemento fundamental de las investigaciones actuales sobre el cerebro es el que se refiere a la relación entre el mundo de las emociones y el de las funciones cognitivas y volitivas. ${ }^{17}$ En este desarrollo histórico del cerebro hubo un momento en el que se llegó a un umbral específico de complejidad, con el cual el funcionamiento del cerebro alcanzó un tipo básico de consciencia y de actividad mental. Estos modos de conducta seguían unidos a los comportamientos emocionales pero van alcanzando autonomía, de tal modo que va emergiendo la agencialidad consciente.

Ahora bien, dentro del nivel de la consciencia ya hicimos referencia a la distinción que establece $\mathrm{G}$. M. Edelman entre la consciencia primaria y la secundaria. La consciencia primaria estaría producida, según Edelman, por la interrelación entre estados metabólicos; el sistema nervioso autónomo y sensomotriz produciría una forma de percepción interna emocional, denominada también por Damasio como percepciones basadas en emociones (Damasio, 1994 y 2003), o consciencia nuclear (Damasio, 1999). ${ }^{18}$ Esta consciencia primaria, o consciencia nuclear, no llega a ser una experiencia de autoconciencia, sino que es el modo como el ser vivo controla el entorno de modo unitario, dándose en estados de vigilia y desapareciendo en situaciones de sueño o de anestesia.

La consciencia secundaria es el resultado de nuevos procesos de integración sistémica del cerebro, en un proceso de simplificación y de integración de funciones. Uno de los objetivos centrales de la investigación más reciente de los neurocientíficos, al mismo tiempo que más difícil de conseguir, es precisamente la aparición de la conciencia reflexiva, ${ }^{19}$ es decir, tratar de explicar qué rasgos específicos tiene que tener el cerebro humano para poseer conciencia reflexiva; o lo que es lo mismo, cómo es posible, y de qué forma, que una serie de fenómenos neuroquímicos den lugar a experiencias conscientes. De momento, la complejidad del cerebro es tal que sólo se llega a vislumbrar el problema y advertir que se trata de un sistema que integra experiencias múltiples desde un centro integrador que no se sitúa en un punto concreto del cerebro, 
sino más bien en el conjunto del sistema, aunque haya zonas cerebrales que se activan de forma especial cuando se producen actos de integración y de conciencia refleja.

Lo que parece claro es que, aunque no podamos explicar cómo se produce, damos por hecho que el cerebro humano se ha complejificado de tal modo que posee capacidad de realizar voliciones libres, no sometidas a constreñimientos biológicos o de otro tipo, sino que posee la capacidad y la necesidad de poder elegir entre diversas posibilidades de acción, teniendo necesariamente que elegir entre una de ellas. Esa es la evidencia interior que alcanzamos en el análisis fenomenológico de nuestras acciones, aunque las neurociencias no sepan explicar más que de forma muy incipiente el funcionamiento del cerebro cuando se dan estas voliciones libres. Este tipo de voliciones supone la capacidad de integrar una gran multitud de procesos de más bajo nivel, desde sistemas superiores de tipo unificador y coordinador de esas funciones. Es decir, "la decisión consciente es un proceso global que implica en definitiva la elaboración de un conjunto de constricciones de control de alto nivel ejercidas sobre una multitud de automatismos inconscientes" (Moreno, 2009, p. 236).
Esta necesaria interrelación de la volición libre con otros niveles inferiores dentro del cerebro es lo que, desde una incorrecta interpretación, ha llevado a algunos autores a negar la libertad y a declararse deterministas, en la medida en que varios experimentos, como los realizados por Libet (1983, pp. 623-642) y Wegner (2002), muestran que la experiencia que tiene el sujeto de las voliciones libres se realiza en momentos posteriores a su inicio real. Las palabras de Wegner son bien significativas de cara a una interpretación determinista de estos fenómenos: "El inicio de un acto voluntario resulta ser un proceso inconsciente del cerebro. Claramente, la voluntad libre para elegir actuar ahora puede no ser debida al agente (consciente), contrariamente a la opinión mayoritaria" (Wegner, 2002, p. 54) y (Moreno, 2009, p. 236).

Esta interpretación es deudora de una idea de libertad propia de una mente no encarnada en un cuerpo, además de entenderla como algo instantáneo y no inscrita en un proceso en el que intervienen con anterioridad momentos inconscientes y emotivos, como es la opinión de otros muchos autores (Petit, 2007, pp. 77-91). La conclusión de ello es, como indica A. Moreno (2009), que:

No es el estado consciente por sí mismo lo que garantiza que la acción sea voluntaria, sino una continuidad de procesos encadenados realizados bajo control de la atención consciente. Desde esta perspectiva, el hecho de que una acción voluntaria 
pueda haberse iniciado antes de ser reconocida como tal no invalida su carácter de acción voluntaria. (Pp. 236-237)

Ya veíamos con anterioridad que Damasio entiende que la dimensión racional de la mente humana se conjuga con las emociones para conformar un acto voluntario, de tal manera que las respuestas emotivas y pre-racionales ante determinados estímulos o circunstancias de nuestro entorno se suceden de modo más o menos automático, sin necesidad de ser controladas por nuestro centro consciente, puesto que resultan ser modos de responder a las emergencias imprevistas, aprendidos durante el proceso evolutivo. Si en el mundo animal este esquema conductual es casi el único que existe, y el que controla de modo suficiente su conducta, como lo muestra el proceso selectivo que les ha permitido sobrevivir, no es difícil entender que en el esquema conductual humano sigan siendo necesarios, de tal modo que actúan anticipándose a las respuestas conscientes y voluntarias, puesto que sin esas respuestas emotivas y pre-conscientes no sobreviviríamos, porque nuestras respuestas conscientes llegarían tarde. Así, las respuestas conscientes y voluntarias vienen después, sirviendo para evaluar la situación, pudiendo la volición afianzar la respuesta emotiva o cambiarla. Y ahí es donde se sitúa el ámbito de la volición y de la libertad, y no tanto en un ámbito absoluto, fuera de los mecanismos físicos de nuestro cuerpo, así como tampoco se dan nuestros actos libres al margen de razones racionales, puesto que, en caso contrario, más que libertad racional sería pura arbitrariedad.

\section{Las características de las acciones libres}

En conclusión, la postura que estamos defendiendo aquí es la de una libertad limitada y situada, resultado de un proceso evolutivo en el que se ha ido conformando la mente humana como consecuencia de un proceso de complejificación cerebral, hasta conformarse una estructura o sistema que dota al ser humano de autoconciencia, autonomía y libertad, entre otras cualidades superiores, que lo convierten en una especie singular (Beorlegui, 2011).
Una vez presentadas las características de las acciones humanas, en contraposición con otro tipo de agencialidad no humana o prehumana, y situada también la emergencia de la volición humana en el entorno evolutivo de los seres vivos, mostrando tanto su continuidad y familiaridad como también su diferencia y ruptura, es el momento de que nos detengamos a analizar las características de las acciones libres de los humanos. 
Ahora bien, en este apartado tenemos que referirnos a dos elementos diferentes pero que están íntimamente relacionados, como son la idea de persona y el doble nivel explicativo de las acciones humanas.

\subsection{Libertad e idea de persona}

La defensa de la libertad exige el reconocimiento de una personalidad o sujeto autónomo, capaz de ser consciente de su relación con el mundo y con los demás, y de poseer al menos un cierto grado de elección entre circunstancias condicionantes.

La existencia del yo se ha venido negando desde los tiempos de Hume, quien lo mismo que negaba la idea de causalidad también ponía en cuestión la consistencia de la idea del yo o sujeto unificador de nuestras acciones. Para Hume, la conciencia viene a ser más bien un plexo o teatro en el que se sitúan nuestras experiencias de todo tipo, pero sin que de ahí se pueda concluir la existencia de un yo substancial, persistente, al que haya que atribuir las diferentes experiencias o acciones. Si lo hacemos se debe a la costumbre, apoyada en la ley de contigüidad y otras similares.

Pero Kant ya advirtió con acierto las insuficiencias del planteamiento empirista humeano, en la medida en que la mente no aparece nunca como una tabla rasa, puesto que la impresión del entorno en el horizonte de nuestras experiencias exige un agente seleccionador y organizador de las mismas. De ahí que Kant distinguiera entre el aspecto fenoménico del yo y el nouménico o esencial. Del análisis de nuestros actos intelectivos y prácticos se puede deducir, tras un análisis trascendental, que se necesita una evidente unidad de apercepción que es la que nos constituye como yo o conciencia. Otra cosa es saber cuál es la esencia de tal conciencia o núcleo de nuestra personalidad, en la medida en que pertenece a la dimensión nouménica $y$, por tanto, incognoscible. Pero lo que sí resulta claro para Kant es la necesidad de dar por hecho la existencia del yo como condición de posibilidad, tanto de nuestros actos intelectuales (ámbito de la razón pura) como de nuestros actos morales (razón práctica).

Como ya sabemos, con el inicio de la psicología científica en la segunda mitad del siglo $X X,{ }^{20}$ se intentó por todos los medios acceder de forma empírica a esa dimensión nouménica de la conciencia sin conseguirlo. Tal fracaso dio lugar a la tesis opuesta del conductismo, negando la existencia de la mente, entendiéndola como un viejo reducto metafísico que había que superar y sustituirla por el estudio objetivo y externo de la conducta (Gardner, 2000, pp. 26 y ss). 
La postura conductista que niega la existencia de la conciencia fue superada, tras medio siglo de dominio casi absoluto en el ámbito norteamericano, por otras teorías sobre la mente como la denominada teoría de la identidad y el funcionalismo. Para la primera, fruto del auge de las incipientes neurociencias, la mente se reduce al cerebro, reduciendo el estudio de la mente a una estrategia de tercera persona que renuncia al acercamiento a lo mental desde la introspección, por considerarla engañosa y poco científica (Rabosi, 1995, pp. 17-42). El funcionalismo se separa del reduccionismo de la teoría de la identidad y del conductismo desde el reconocimiento de la diferencia entre la base cerebral y la funcionalidad de lo mental, explicando la diferencia y relación entre lo cerebral y lo mental desde la metáfora de los ordenadores o computadoras en los que se da una diferenciación, y a la vez una relación entre el soporte material (hardware) y la programación (software), dando lugar a las diversas investigaciones sobre la inteligencia artificial (García Carpintero, 1995, pp. 43-76).

En la actualidad, dentro del amplio panorama de posturas dentro de la denominada filosofía de la mente, ${ }^{21}$ nos hallamos ante tres grandes posturas fundamentales que tienen su relación directa con el tema de la libertad. La primera es la que, basada en una versión estrecha de la ciencia, considera que la única estrategia de acceso a lo mental es la de tercera persona, postura que pretende reducir lo mental a datos objetivos, bien sea de naturaleza conductual o cerebral. En cualquiera de los dos casos se rechaza el camino de la introspección como engañoso y acientífico. Esta postura va de la mano de una concepción reduccionista de la realidad humana y, por tanto, tiende en la gran mayoría de los casos a negar la libertad, reduciendo nuestros actos a meras consecuencias del funcionamiento del cerebro.

La postura dualista defiende la existencia del alma, conciencia, yo o subjetividad, como una realidad autónoma de lo corpóreo y cerebral que tiene capacidad de intervenir en el funcionamiento del cerebro. ${ }^{22}$ Este posicionamiento defiende la libertad y una idea fuerte de persona y de subjetividad, pero resulta difícil conjugar sus afirmaciones con la autonomía de la realidad material, tesis central de la ciencia actual.

Se dan varias posturas que se sitúan entre ambos extremos; el dualista y el reduccionista, como son los diversos funcionalismos y los emergentismos sistémicos. ${ }^{23}$ Ambos planteamientos defienden la existencia de la libertad y una concepción fuerte de la persona como condición de posibilidad de la autonomía del ser humano y de su dignidad ética. Pero el funcionalismo tiene muchas dificultades para escapar de un 
dualismo larvado al defender la metáfora del ordenador y la diferencia radical entre la programación y la base material, lo que le lleva a menospreciar los datos y la influencia del cerebro en la dimensión mental, ello en contra de lo que las neurociencias nos vienen mostrando. En cambio, los emergentismos consideran lo mental como la dimensión estructural y sistémica de lo cerebral y corpóreo, por lo que no se sitúa de espaldas a las neurociencias (como el funcionalismo), sino que recoge sus aportaciones como dato esencial de lo mental, aunque no lo reducen al mero funcionamiento de las diversas partes del cerebro sino que diferencian entre las partes y el todo sistémico, situando en el sistema (cerebral o corpóreo) la agencia del comportamiento humano.

En definitiva, las disputas con los determinismos cerebrales o científicos tienen de fondo, tanto en el nivel epistemológico (el modo de conjugar el nivel científico con el filosófico) como en el nivel ontológico, el problema de la aceptación o negación de la idea de persona o de sujeto.

Como indica Ph. Clayton, en las discusiones sobre el problema de la libertad se necesita explicitar y revisar el modo de entender las acciones humanas y la idea de persona que cada autor posee o presupone. ${ }^{24}$ Dejamos el aspecto de la acción para el apartado siguiente, y vamos a centrarnos en el presupuesto de la idea de persona. Clayton nos pone como ejemplo el modo como D. Dennett conjuga la idea de persona y su concepción de libertad. Dennett considera, al estilo de G. Ryle, que en el análisis de lo mental cometemos un error categorial al pensar que en nuestro interior existe una entidad autónoma que dirige nuestra conducta. De ahí que, como trató de hacer el conductismo lógico, ${ }^{25}$ haya que purificar nuestro lenguaje mentalista para reducirlo a sus explicaciones objetivas y científicas. Para Dennett, "tener una vida interior - ser algo que uno siente ser- significa, en esta concepción, tener un cierto tipo de organización funcional" (Dennett, 1996, p. 248). ${ }^{26}$

De este modo, Dennett se sitúa en cierta medida en la línea del funcionalismo, pero entendiendo la funcionalidad de la conciencia en el horizonte de la selección natural: la mente es un mecanismo generado por la evolución para una mejor supervivencia. De este modo, considera que hay que cambiar la idea espiritual de la mente por una teoría naturalizada como la suya. Este modo de entender lo mental supone interpretar de un modo muy especial nuestro mundo interior, el modo como cada uno de nosotros nos experimentamos como un yo. En la medida en que somos un sistema construido por la evolución para sobrevivir, el propio sistema no es consciente de su propia realidad. Es un sistema oscuro y no consciente, 
aunque visto desde fuera, analizando su comportamiento, se dirige inteligentemente a una meta y funciona como si supiese lo que quiere y cómo lo va a conseguir. Visto desde fuera, genera la ilusión de que es consciente, pero no lo es. "Dentro de vuestro cerebro, indica Dennett, también es todo oscuridad, y todos los procesos que se producen en vuestra materia gris ocurren sin ser percibidos y sin percibir" (Dennett, 1996, p. 165).

Dennett entiende que a veces resulta útil seguir hablando de intencionalidad de nuestros actos, pero tiene que entenderse en un sentido regulativo, al estilo kantiano, es decir:

La actitud intencional es la estrategia que consiste en interpretar el comportamiento de una entidad (persona, animal, artefacto, lo que sea) tratándola como si fuera un agente racional que, "teniendo en cuenta" sus "creencias" y sus "deseos", rigiera la "elección" de sus "actos" (Dennett, 1996, p. 40). ${ }^{27}$

Por tanto, para Dennett es un error subjetivo pensar que el lenguaje intencional que usamos en el lenguaje común refleja la realidad subjetiva de nuestra mente.

Clayton nos indica que:

Los intérpretes han llamado a esto una teoría "deflacionista" de la mente. La deflación ocurre -se nos dice- en cuanto caemos en la cuenta de que en el centro de la experiencia humana no hay tal cosa como un sujeto cartesiano. (Clayton, año, p. 43)

El problema está en que resulta difícil convencernos de que eso que experimentamos continuamente es sólo un sueño y un error, y que nuestras acciones no son fruto de una deliberación y una decisión libre, encaminada a un fin previamente elegido.

Eso es para Dennett, al igual que para G. Ryle, como ya dijimos, un error categorial, puesto que si nos metemos en un cerebro humano, por más que lo auscultemos hasta el último rincón, nunca encontraremos un yo o una mente, al igual que en el ejemplo de Ryle; por más que se enseñe a un visitante todos los edificios de una universidad, nunca le podremos enseñar "la universidad” (Ryle, 1967). Por tanto, una visión adecuada, científica, del problema conlleva la desaparición, la deflación, de un concepto erróneo como el yo y la mente consciente. Claro que, como hemos dicho ya, el gran enemigo de este paso purificador es la psicología popular, 
propia de nuestro mundo de la vida, que produce lo que él denomina "la ilusión del usuario", porque tras analizar el proceso cerebral de pensar y de actuar "no hay un único y definitivo 'flujo de conciencia', porque no hay un cuartel general central, ni un teatro cartesiano donde 'todo se junta'" (Dennett, 1996, p. 267). ${ }^{28}$

La verdad es que este tipo de explicaciones van tan en contra del sentido común, y se apoyan en una explicación tan reduccionista y tan poco convincente de las posibilidades de entender el funcionamiento del cerebro, que nos resultan dogmáticas e ingenuas. Que no se encuentre el yo tras la inspección del cerebro no significa que la única forma de entenderlo sea considerándolo como una parte del cerebro. Precisamente, el objetivo central de las investigaciones más interesantes de las neurociencias es explicar cómo unos fenómenos físicos y bioquímicos dan lugar a los sucesos mentales que aparecen en nuestra conciencia. ${ }^{29}$

Las tesis emergentistas tratan de explicar el problema del yo y de la mente como consecuencia de un proceso evolutivo de complejificación del cerebro, viendo una diferencia notable y esencial entre las propiedades de las partes del cerebro y las del sistema completo, fenómeno sistémico que no ocurre solamente en el cerebro sino en otros muchos ámbitos de la realidad, cosa que parece negar dogmáticamente los reduccionistas como Dennett. Pero es faltar a la objetividad prescindir de la experiencia de la autoconciencia porque no puede ser explicada desde la óptica de la primera persona, deduciendo de ahí que se trata de un simple error y un sueño. Considero que es mucho más seria y objetiva la postura de J. Searle cuando defiende que cualquier postura dentro de la filosofía de la mente no acertará mientras no trate de explicar el fenómeno de la conciencia, y desde ahí proponga una postura que respete la autoconciencia, al mismo tiempo que las aportaciones de las neurociencias (Searle, 1995, pp. 413-443).

En conclusión, se da una directa y estrecha relación entre las tesis que tengamos sobre la persona humana y sobre la libertad, como el mismo Dennett reconoce. La idea que tiene él de persona, como un fenómeno erróneo y reducible al mero funcionamiento físico del cerebro, le lleva a negar la libertad y la responsabilidad. Para Dennett, las ideas de libertad, responsabilidad e intencionalidad son meras ideas regulativas, de tal modo que, aunque las atribuimos a las personas, no hay que entenderlas en el sentido tradicional. De todos modos, a pesar de que Dennett entiende que las personas no somos responsables de nuestros actos al estilo de lo que tradicionalmente se entiende, el concepto de responsabilidad sigue siendo pertinente para él, 
pero simplemente viene a decir que hay ocasiones en que las personas son responsables de sus acciones porque podrían haber actuado de otro modo, pero en esas actuaciones no son totalmente autónomas, sino resultado de circunstancias que no dominan, puesto que no son libres en el sentido pleno del término. ${ }^{30} \mathrm{Es}$ decir, parece que somos libres pero no acabamos de serlo del todo.

Con estas reflexiones nos reafirmamos en el hecho de que las posturas sobre la libertad no se resuelven en el ámbito de los hechos objetivos, científicos, sino que suponen unos aprioris de tipo filosófico y cosmovisional. Desde un determinado punto de vista, resultado de unas premisas filosóficas, antropológicas y ontológicas específicas, resultan lógicos y aceptables los planteamientos reduccionistas pero desde otras premisas diferentes, más antropocéntricas, tales planteamientos resultan dogmáticos e ingenuos. Nosotros partimos de un planteamiento emergentista, como ya hemos indicado, que entiende lo mental y la persona humana en clave sistémico, sin caer en la ingenuidad de que por eso ya hemos resuelto el enigma de la relación entre cerebro y mente, ni tampoco los enigmas y misterios del yo y de la persona humana, cargada de una densidad ontológica y de una dignidad ética y metafísica que no son empíricamente explicables, aunque sí totalmente postulables para poder entender en toda su profundidad la realidad humana.

Nos queda, a continuación, la tarea de explicar el funcionamiento de la libertad en el horizonte de las acciones humanas, una vez dado por hecho la densidad del yo y de la persona y, por tanto, la pertinencia de defender la libertad como ingrediente esencial y distintivo de nuestro actuar.

\section{El doble nivel explicativo de las acciones humanas}

Se trata de explicar a continuación cómo advertimos la libertad en el juego de la experiencia que tenemos de ella, desde la confluencia de la introspección y de la evidencia de la relación causa-efecto en el ámbito de los acontecimientos materiales. Para ello, vamos a volver a referirnos a algunos aspectos de la teoría de la acción, desde la que comenzamos este amplio apartado, de la mano sobre todo de John Searle. ${ }^{31}$

Para Searle:

La experiencia del libre albedrío se refleja en la estructura lógica de las explicaciones de nuestros actos. En resumen, debido a la existencia del intervalo, las explicaciones que aluden a nuestros procesos de toma racional de decisiones no 
son formalmente deterministas del modo en que las explicaciones ordinarias de los fenómenos naturales son formalmente deterministas. (Searle, 2005, p. 47) ) $^{32}$

La postura de Searle se sitúa, como ya dijimos en su momento, en el horizonte del análisis de las acciones humanas, y ahí es donde se nos muestran los dos niveles en conflicto: el del ámbito de los sucesos físicos de nuestro cuerpo, en donde la relación causa-efecto se conforma con un esquema determinista, y el ámbito de las decisiones mentales, en donde se advierte una concatenación entre motivos y acción, dentro de la cual se da, como dice J. Searle, un intervalo o brecha (gap), una relación no determinista, lugar donde se sitúa precisamente la libertad.

El tipo de explicaciones de las acciones humanas voluntarias es

distinto al de las acciones naturales. En este segundo caso, vemos que un acontecimiento físico (caída de una piedra) es la causa de otro (rotura de una botella). En cambio, en el caso de las acciones humanas voluntarias intervienen razones cuya relación causal respecto a sus consecuencias es de diferente tipo. Para entender esto tenemos que postular un yo o un ego (Searle, 2005, p. 50). Ya hemos hecho referencia a todo esto en el apartado anterior, por lo que no nos vamos a detener en este punto.

Una vez aceptada la existencia de un yo o persona, se trata de hacer ver que:

La forma lógica de la explicación racional es bastante diferente de las explicaciones causales estándar. La forma de explicación no consiste en dar condiciones causalmente suficientes, sino en indicar la razón por la cual el agente ha actuado. (Searle, 2005, p. 50)

$Y$ el resultado de ello es, en forma de un círculo virtuoso, "como si las explicaciones de acciones racionales exigieran postular la existencia de un yo irreductible, un agente racional, además de las secuencias de acontecimientos" (Searle, 2005, p. 50). Es una lógica similar a la empleada por Kant contra los planteamientos empiristas de Hume, en la medida en que posturas reduccionistas como las de Dennett están mostrando una clara utilización implícita (la unidad e intencionalidad del pensamiento y de la acción) de lo que están negando de modo explícito.

La tesis que Searle propone, y se esfuerza en hacerla plausible y convincente, es que "las explicaciones basadas en razones no son explicaciones causales ordinarias. Aunque tienen un componente 
causal, su forma no es 'A causó B'” (Searle, 2005, p. 53). No cabe duda de que esta afirmación es problemática porque resulta difícil el mostrar que su relación causal es de otro tipo, pero es evidente que la razón que está al fondo de un acto, no supone "una causa suficiente del acontecimiento de que se trate, sino que especifica el modo como un yo racional consciente actuó sobre la base de una razón, cómo un agente hizo eficaz una razón actuando libremente a partir de ella" (Searle, 2005, p.53). Y ello, insiste Searle, vuelve a exigir que postulemos necesariamente la existencia de un yo, en la medida en que las razones que indicamos "explican por qué un yo actuó de una determinada manera. Explican por qué un yo racional, actuando en el intervalo de que hablábamos, actuó de una manera y no de otra, al especificar la razón a partir de la cual actuó dicho yo" (Searle, 2005, pp. 53-54).

El problema clave para Searle consiste en percibir, a la hora de explicar las acciones humanas, la existencia de un intervalo entre los dos niveles de explicación, y saber entenderlo de la forma adecuada. Para entender dicho intervalo hay dos modos de acceso, como indica Searle: experiencial y lingüístico. Es decir, tenemos la experiencia interior de actuar libremente en ese intervalo y el reflejo de ello se da en el modo como lo expresamos lingüísticamente. Eso significa que damos por hecho, en las expresiones lingüísticas, que hay una entidad (un yo) que actúa en el intervalo, y explicamos su actuación dando razones (Searle, 2000a, cap. 3). ${ }^{33}$

El yo, por tanto, actúa por razones (aunque cabe preguntar por qué estas razones y no otras), y las expresamos en las explicaciones de nuestros actos. Ahora bien, esas explicaciones no son del estilo de las relaciones causales en los acontecimientos naturales, como ya lo hemos repetido más arriba.

Está claro que los actos y su expresión lingüística tienen que tener base neurológica. En la relación entre mente y cerebro, J. Searle se define como emergentista, ${ }^{34}$ en la medida en que para él "la conciencia es una característica de nivel superior, o sistémica, del cerebro producida por el comportamiento de elementos de nivel inferior, tales como las neuronas y las sinapsis" (Searle, 2005, p. 58). El problema está ahora en mostrar cómo se comportan las neuronas y sus interconexiones sinápticas para producir un cerebro que permita las acciones libres. Es fundamental, para Searle, que sepamos conjugar los dos niveles del cerebro: el sistémico y el microscópico.

En el nivel sistémico tenemos conciencia, intencionalidad, decisiones e intenciones. En el nivel microscópico tenemos neuronas, sinapsis y neurotransmisores. Las características 
propias del nivel sistémico son efecto del comportamiento de los elementos del nivel microscópico, y se realizan en el sistema compuesto por los elementos del nivel microscópico. (Searle, 2005, p. 59).

Pero la cuestión problemática viene a continuación, puesto que "si suponemos que hay un intervalo en el nivel superior cuando se adopta una decisión racional, ¿cómo podemos representar dicho intervalo en el nivel neurobiológico? A fin de cuentas, un intervalo semejante no existe en el cerebro" (Searle, 2005, p. 60). La cuestión central está, por tanto, en mostrar si durante la fase de deliberación, en la que se nos presentan diferentes opciones, y en el momento de optar por una de ellas, se realizan en un sistema neurológico totalmente cerrado y determinado.

En el caso de que el sistema estuviera determinado, tendríamos la experiencia subjetiva de libre albedrío, pero en el nivel neurobiológico no habría tal, sino una concatenación de causas y efectos determinados. Esa es la tesis del determinismo psicológico, como es el caso de Dennett, y también del compatibilismo. ${ }^{35}$ Pero entenderlo así supondría para Searle la aceptación del epifenomenismo, en la medida en que la experiencia subjetiva de libertad no realizaría ninguna función causal sobre el cerebro y el cuerpo. A muchos científicos les parece una solución válida pero, como indica Searle, "según esta conclusión, la evolución nos gastó una broma de proporciones colosales. La evolución nos proporcionó la ilusión de la libertad, pero no es nada más que eso: una ilusión" (González Sanz, 2007, p. 64).

La inconsistencia del epifenomenismo se advierte imaginando, nos dice Searle, un robot programado para tener la sensación psicológica de ser libre sin serlo. Todos sus movimientos están determinados por la programación con la que ha sido diseñado, pero dentro de ese programa habría un estado especial que sería la ilusión de ser libre. Esa ilusión falsa, al igual de lo que indica el epifenomenismo, no influiría causalmente en el soporte material para cambiar su comportamiento. Lo que orientaría sus actuaciones serían los elementos del programa con el que ha sido construido, no el estado ilusorio de ser libre, puesto que no se daría una causalidad hacia abajo, esto es, del estado ilusorio de libertad hacia la base material del robot. La cuestión que plantea esto es; para qué se le dota al robot de ese estado ilusorio si no tiene ninguna función causal. La misma sensación de inutilidad en el caso del robot produce la tesis epifenomenista en el caso humano, puesto que nos encontraríamos con que la libertad ilusoria, aunque entendamos que es fruto 
de la evolución, no tendría ninguna funcionalidad para la actuación y la supervivencia del individuo. Sería tan ilógico y disparatado como decir que la evolución nos dota de la capacidad de ver o de oír, pero que nuestras experiencias visuales y auditivas son meras experiencias ilusorias, sin que tengan ninguna funcionalidad de cara a la supervivencia. Se advierte, por tanto, el precio y las consecuencias de irracionalidad que hay que pagar por afirmar, sin pruebas, que la conciencia de libertad es una mera ilusión que no responde a una realidad que funciona con leyes totalmente diferentes, determinadas.

Veamos ahora la hipótesis contraria y la explicación del proceso de libertad. Cuando deliberamos y decidimos lo hacemos en un ámbito de libre albedrío apoyándonos en fenómenos cerebrales causalmente suficientes en el terreno neurobiológico. El asunto está, lo volvemos a repetir, en cómo es esto posible, puesto que en el funcionamiento neurobiológico no hay lagunas ni intervalos. Para entender cómo se relaciona la conciencia con el cerebro, Searle considera que "la conciencia es una característica del sistema en su conjunto. La conciencia está presente, literalmente, en todas aquellas porciones del cerebro en las que la actividad neuronal produce y realiza la conciencia” (González Sanz, 2007, p. 66). La conciencia es una propiedad o característica del cerebro humano que no reside en una parte del mismo sino en el conjunto sistémico, al igual que la solidez de un material es el resultado de las características en su conjunto de los átomos y demás componentes de ese material.

Searle entiende que este ejemplo es una analogía que no hay que tomarla al pie de la letra porque la solidez de un material es un fenómeno determinista y no ocurre lo mismo en el caso de la conciencia; y, en segundo lugar, porque la solidez del material es reducible ontológicamente al comportamiento de sus átomos y moléculas, pero en el caso de la conciencia no podemos realizar una reducción ontológica similar. "Ello es debido,-nos indica Searle-, a que la ontología de primera persona de la conciencia no es reductible a una ontología de tercera persona" (González Sanz, 2007, p. 67).

En definitiva, la visión sistémica del funcionamiento del cerebro para conformar la conciencia hace que la forma de ser de los elementos del sistema determina el estado del sistema, en este caso de la conciencia.

Pero ningún estado determinado de las neuronas y de la conciencia es causalmente suficiente para producir el estado inmediatamente posterior. El paso de un estado al siguiente se explica por los progresos racionales de pensamiento que tienen 
lugar en el estado inicial de las neuronas y de la conciencia. En todo instante, el estado total de la conciencia está determinado por el comportamiento de las neuronas, pero, de un instante al siguiente, el estado total del sistema no es causalmente suficiente para determinar el estado que viene a continuación. El libre albedrío, suponiendo que exista, es un fenómeno que se da en el tiempo. (González Sanz, 2007, pp. 68-69)

Está claro que la hipótesis emergentista, entre cuyos defensores está J. Searle, no supone creer que se sabe explicar cómo causa o produce el funcionamiento neurobiológico del cerebro la conciencia o el yo. Lo que sí defiende es que esa causación, sea cual sea el modo de realizarla, es obra del conjunto sistémico del cerebro, no consecuencia de la actuación de una parte del mismo. De este modo, podríamos decir que:

Somos robots conscientes cuyos estados de conciencia están determinados por procesos neuronales y, al mismo tiempo, actuamos a veces a través de procesos conscientes no deterministas (de ahí los procesos neuronales) por los que nuestro yo racional adopta decisiones a base de razones. (González Sanz, 2007, p. 77)

El reto está ahora en proponer cómo pensamos que podría funcionar el cerebro para que las cosas sucedan de esta manera. Sólo podemos proponer hipótesis que resulten plausibles. Searle considera que para que ello sea posible se necesitan tres condiciones, tratando de explicar cómo podría funcionar el cerebro para que se cumplan:

a. "La conciencia, en tanto que causada por procesos neurales y realizada en sistemas neuronales, funciona causalmente como motor del cuerpo" (González Sanz, 2007, p. 78). Esta condición ya la ha explicado Searle repetidas veces. La condición sistémica del cerebro (y del cuerpo humano en su totalidad) hace que la conciencia esté causada por los procesos neurales concretos, y la realización de las propiedades del cerebro es precisamente el conjunto de actos mentales que constituyen la conciencia, pero no se trata de un epifenómeno sino que la conciencia actúa causalmente sobre el cuerpo.

b. "El cerebro causa y sostiene la existencia de un yo consciente capaz de tomar decisiones racionales y traducirlas en acciones" (González Sanz, 2007, p. 78). La conciencia no es lo mismo que el yo, aunque ambas realidades están 
relacionadas. Para Searle, "el yo equivale a la suma del carácter propio de un agente consciente más la racionalidad consciente" (González Sanz, 2007, p. 79). El yo reúne, por tanto, una serie de elementos como el campo unificado de la conciencia, la capacidad de deliberar sobre la base de razones y la capacidad de emprender y llevar a cabo acciones, esto es, el estar dotado de volición (González Sanz, 2007, pp. 79-80).

c. "El cerebro es de tal naturaleza que el yo consciente es capaz de adoptar y ejecutar decisiones en el intervalo, donde ninguna decisión ni acción está determinada de antemano, bajo condiciones causalmente suficientes y, sin embargo, ambas se explican racionalmente por las razones sobre cuya base actúa el agente" (González Sanz, 2007, p. 81). Ya sabemos que esta condición es, para Searle, la más difícil de explicar y de hacer plausible, porque el mismo cerebro causa los procesos neurobiológicos a la vez que las experiencias propias de lo mental y del agente racional.

Eso supone introducir en el cerebro un ámbito claro de indeterminación, aunque hay que diferenciar entre la libertad y la indeterminación. La libertad supone indeterminación y racionalidad. La indeterminación es la condición necesaria pero no suficiente para la libertad, pero la indeterminación que se da en la libertad no es el mero hecho de que las acciones no están determinadas, sino sometidas al azar y a la probabilidad. La indeterminación de la libertad no es la del caos que causa incertidumbre pero no indeterminación, y tampoco le resultan convincentes a Searle las tesis sobre el indeterminismo cuántico, defendidas sobre todo por Penrose y otros estudiosos, y aplicadas a la explicación del surgimiento de la conciencia y de la libertad. ${ }^{36}$ Searle considera que todo indeterminismo de la naturaleza es indeterminismo cuántico, pero no le resultan convincentes las tesis de quienes, como Penrose, consideran que la conciencia se debería al hecho de que los microtúbulos (elementos que conforman las neuronas), en un momento determinado, estén funcionando con un potencial de acción de un número determinado de hertzios.

El indeterminismo cuántico, apoyándose en los descubrimientos de la mecánica cuántica y en el principio de indeterminación de Heisenberg, basa la defensa de la libertad en la evidencia de que la realidad subatómica se rige no por leyes determinísticas sino probabilísticas; y, en gran medida, por azar. Vivimos en un mundo abierto, según la teoría cuántica, no cerrado como pensaba la física determinística clásica. ${ }^{37}$

Pero el problema está en que ese modo de entender las cosas no aboga a favor de la libertad humana 
sino del azar y la casualidad. Mostrar que las leyes que rigen no sólo el mundo de las partículas atómicas sino otros ámbitos de la realidad, como han mostrado la teoría del caos o de las catástrofes, ${ }^{38}$ no supone más que afirmar que el mundo en el que vivimos hace posible y permite la libertad, pero la simple estructura probabilística de la realidad no hay que confundirla con la libertad. Como es evidente, no siguen los mismos parámetros de conducta un dado, o cualquier juego de azar, que un ser humano. A un mecanismo azaroso no se le pueden pedir responsabilidades porque no es consciente de lo que hace, ni podemos decir, por tanto, que ha decidido libremente lo que hace, cosa que sí ocurre en el ámbito de las acciones libres humanas.

Basándose en la indeterminación cuántica, hay autores como R. Penrose ${ }^{39}$ y Hameroff y Wat ${ }^{40}$ que consideran que el fenómeno de la conciencia se produce en el ámbito del funcionamiento de los microtúbulos y las tubulinas (subunidades con las que están compuestas las neuronas), y que actúan como partículas cuánticas. Según estos autores, las moléculas de las tubulinas pueden adoptar dos estados diferentes ( 0 y 1 ), similares a la combinación binaria del ámbito de las computadoras. Así, cada microtúbulo se comportaría como un ordenador en pequeño:

Capaz de llevar a cabo computaciones simples, que se extenderían sobre áreas muy amplias de la corteza cerebral, dando lugar a una actividad cuántica a gran escala, en la que se basaría el fenómeno de la consciencia y de la capacidad de elección. (González Sanz, 2007, p. 125).

Estas propuestas han sido defendidas con concreciones y alternativas muy dispares, ${ }^{41}$ y no puede ser de otra manera, en la medida en que se trata de hipótesis de trabajo que distan mucho de tener evidencias empíricas y de haber sido contrastadas científicamente, además de presentar dificultades de coherencia interna. En primer lugar, aunque se haga referencia a fenómenos cuánticos, que no son fácilmente explicables ni controlables, estaríamos hablando siempre de partículas materiales que interactúan entre sí, pero no se muestra en último término cómo es posible que una realidad no material (la mente) pueda influir sobre la materialidad del cerebro, y al revés. Además, está el problema de explicar cómo los diferentes microtúbulos pueden formar una unidad funcional que actúe al unísono con los millones de neuronas que participan en una decisión, no sabiéndose, por otra parte, cómo y quién inicia esa actividad (González Sanz, 2007, p. 125). De todos modos, estas dificultades concretas no 
implican descartar del todo estos planteamientos, ni negar que no sea este camino de investigación un ámbito de gran interés que quizás en el futuro pueda aportar soluciones interesantes. De momento, sus afirmaciones suscitan muchas interrogantes y no pocas dudas $y$ rechazos.

Searle ha estudiado a fondo las propuestas de Penrose, y no le resultan en absoluto satisfactorias. ${ }^{42}$ Según él, presentan dos grandes limitaciones: no explica, en primer lugar, cómo se salta de un fenómeno neurobiológico de indeterminación a otro de tipo racional, como son las decisiones de la libertad. $\mathrm{Y}$, en segundo lugar, esta explicación parece oponerse a la tesis emergentista del funcionamiento sistémico del cerebro. Es decir, no se ve que las cualidades de las partes (indeterminación cuántica) tengan que ser las cualidades del todo (el cerebro como sistema que causa la conciencia). En definitiva, para Searle:

El hecho de que los fenómenos individuales sean aleatorios no implica aleatoriedad también en el plano sistémico. La indeterminación en el nivel microscópico puede explicar (...) la indeterminación del sistema, pero la aleatoriedad en el nivel microscópico no implica por ello aleatoriedad en el plano sistémico. (Searle, 2005, p. 86)

Como puede verse, la postura que defiende la libertad no supone una derrota definitiva del determinismo y una demostración contundente de su propia postura. Está claro que no es posible una demostración definitiva (en el ámbito empírico) ni de la libertad ni del determinismo, pero sí cabe mostrar las contradicciones de las posturas que niegan la libertad. Searle ha mostrado la incoherencia del epifenomenismo y del compatibilismo desde el momento en que se opondría al modo como funciona el proceso evolutivo de la selección natural.

Al mismo tiempo, el determinismo, como ya vimos en su momento y Searle nos lo advierte también, incurre en contradicciones flagrantes como muestra a partir de la argumentación que le propuso un oyente de una de sus conferencias. El oyente le pregunta si aceptaría la tesis determinista si se demostrara que es verdadera, y Searle argumenta diciendo que esa pregunta supone aceptar las reglas de juego de la racionalidad que suponen que, en un diálogo entre contrincantes de opiniones diferentes, uno acepta o rechaza un argumento tras valorarlos y decidirse por uno libremente. Nadie acepta que le den la razón por amenazas o cualquier otro motivo que no sea por el peso de las razones. ${ }^{43}$ Por tanto, el que 
ha planteado la pregunta le pide a Searle que haga libre y racionalmente una predicción (si aceptaría o no el determinismo, si se demostrara que es verdadero), cuando da por cierto que no somos libres.

En definitiva, como indica Popper, ${ }^{44}$ es posible que estemos determinados y no seamos libres, pero si lo somos no es porque sea demostrable racionalmente (cuando se analizan los determinismos vemos que sucede lo contrario: se trata de una postura llena de contradicciones), (Beorlegui, 2012, pp. 230-236) sino porque lo somos al margen de que nosotros lo pensemos o no, estemos convencidos de ello o no, pero el precio de este modo de pensar es condenarnos a la más absoluta irracionalidad, en la medida en que el determinismo parece apoyarse en el hecho de que todo lo que pensamos y digamos (tanto si defendemos el determinismo o la libertad) es puro sueño e ilusión. El sentido común y el mundo de la vida en el que nos movemos y estamos asentados rompen ese modo de pensar y nos hace experimentar como más coherente la experiencia de la libertad.

\section{Para concluir}

Como hemos podido ver, el estudio de la subjetividad, así como sus distintas propiedades o características (la autoconciencia, la libertad, entre otras), constituye un tema de reflexión que posee unas dificultades específicas. Tanto la estrategia de primera persona (introspección) como la de tercera (tratar la mente como un objeto más, sometido a la metodología científica) han mostrado su insuficiencia. De ahí que, refiriéndonos al caso concreto de la libertad, nos encontramos abocados o a la simple autoevidencia de la misma, con el riesgo de sospecha permanente de autoengaño $o$ al riesgo de su negación (determinismo), en la medida en que el intento de dar cuenta de ella escapa siempre a la objetivación científica.
El centro de las reflexiones de este artículo se ha orientado a mostrar que el camino más fructífero para salir de esos dos callejones sin salida es acercarnos a la reflexión sobre la libertad desde la óptica de la filosofía de la acción. Eso nos lleva a distinguir entre conducta y acción, mientras que en la reflexión sobre la primera se tiende a centrarse en la mera descripción externa del comportamiento humano, en la segunda se profundiza en su interioridad, advirtiendo en la sucesión de sus diversos momentos un entrelazamiento de los mismos, guiados por una finalidad. El comportamiento de un ser vivo, tanto animal como humano, posee una tendencia a un objetivo que lo diferencia de la trayectoria de un objeto inanimado 
que se rige por simples leyes físicas y químicas. $Y$ dentro de los seres vivos, aun en el caso de los más complejos y cercanos a la especie humana, la diferencia se halla en el hecho de que, en el caso de los humanos, la acción persigue un objetivo presupuesto y elegido de forma autoconsciente y libre (aunque no en todos los casos), mientras que no ocurre lo mismo en el caso de los demás animales.

Por tanto, a la hora de acercarnos a estudiar la interioridad y la libertad humanas, nos encontramos con que no es adecuado ni el camino de la objetivación científica, ni el cortocircuito de la introspección (en contra de la propuesta cartesiana o husserliana). En la medida en que los humanos somos seres interpersonales, el acercamiento a nuestro yo no puede hacerse de forma completa en el ejercicio solipsista de mirarse a uno mismo sino a través de la salida al otro. De ahí que sea tan sugerente el título del libro de P. Ricoeur (1996), Sí mismo como otro, profundo análisis de la subjetividad humana desde el horizonte de la hermenéutica y de la filosofía de la acción. Parece curioso que el acercamiento a uno mismo no se pueda realizar de forma certera en la soledad de la introspección sino en el camino largo de la vuelta a sí mismo tras haber pasado por el encuentro y la mirada del otro. $Y$ es que lo original y punto de arranque no consiste en un yo que sale hacia el otro, porque el yo no puede ser ni tomar conciencia de sí sin el otro, sin el contexto del diálogo interpersonal. Como ya indicó Ortega y Gasset (1957), el yo, aunque lo consideremos la primera persona gramatical, no es un punto de salida sino de llegada. Comenzamos viviéndonos en la impersonalidad del ámbito de la gente, para ir poco a poco teniendo conciencia, dentro del entorno de la impersonalidad de los diversos él o ella, de la singularidad de un tú, que despierta e invita al yo a ser persona, como un alter tú. Somos reciprocantes de los otros, dentro de la nostridad; esto es, nos hacemos y tomamos conciencia en el entorno del nosotros. Sólo en este ambiente y entorno interpersonal es como se puede entender y dar razón de la auténtica esencia de la conciencia y de la personalidad humana, y sólo en ese intercambio dialógico de acciones e interacciones (acción comunicativa) es como descubrimos y atisbamos la consistencia de la subjetividad y de la libertad. $Y$ en ese ámbito de la acción comunicativa es donde se percibe una cierta fusión de perspectivas, de primera y tercera persona; esto es, la reflexión sobre la acción la realizamos desde fuera, pero percibiendo un contenido interior sin el cual no se entiende la dinámica de la acción. Esta fusión de las dos caras es lo que hacía decir a Ortega y Gasset que el cuerpo es carne, expresión;45 esto es, percibimos la presencia del otro, al otro en acción, como un todo único, en el 
que la carne es mediación de otra cosa que está detrás, sino expresión en sí misma de su interioridad, al igual que en una palabra percibimos al mismo tiempo el significante y el significado, y no tanto como la unión de dos cosas extrínsecamente emparejadas (dualismo).

Junto al componente interpersonal, hay que hacer referencia al factor biológico y cerebral como segunda condición de posibilidad de la conciencia y la libertad. Sólo un cerebro como el humano es capaz de hacer emerger y posibilitar la autoconciencia y la libertad. Ahora bien, sólo desde el horizonte de las neurociencias no es suficiente para dar cuenta y llegar a demostrar o negar la libertad. El estudio científico del cerebro no nos lleva más que a descubrir el soporte biológico de nuestro comportamiento, pero no nos permite descubrir ni adentrarnos en el terreno de las motivaciones y finalidades del mismo. Ya hemos indicado que, entre las diferentes posturas que se disputan desde hace algunas décadas la explicación del ya antiguo problema de las relaciones alma-cuerpo, mente-cerebro o mente-cuerpo, el paradigma al que nos adscribimos es el emergentista que estudia la relación mente-cerebro como un sistema o estructura en el que hay que distinguir las capacidades de sus partes y las del todo. Sólo desde el sistema cerebral en su totalidad es posible explicar las cualidades más específicas y complejas de la subjetividad humana como son la autoconciencia, la libertad, el lenguaje simbólico y la específica complejidad del pensamiento humano, pero esto no pasa de ser un modelo explicativo que se limita a realizar constataciones de hecho, pero no puede explicar cómo un conjunto complejo de funciones biológicas del cerebro pueden dar de sí todo el conjunto de fenómenos psíquicos. Junto a los emergentistas que insisten en atribuirlo a la virtualidad del sistema o estructura, hay otro tipo de emergentistas, como Penrose, que se esfuerzan en ahondar las explicaciones sobre el surgimiento de la mente apelando a la dimensión de los fenómenos cuánticos.

Son todavía hipótesis que tienen que comprobarse tanto en su dimensión científica como filosófica, pero al menos tienen la virtualidad de que sólo el comportamiento de la realidad en su dimensión cuántica parece tener propiedades similares a las mentales, como son la capacidad de unificar los fenómenos y la indeterminación. $Y$ esas son, precisamente, las cualidades más específicas de lo mental: unifica las experiencias en un yo que se vive como agente libre y no determinado del todo.

En definitiva, el fenómeno de la libertad se nos presenta como un fenómeno de una gran complejidad que sólo se entiende desde dos condiciones de posibilidad: la maduración de nuestro cerebro 
hasta alcanzar la complejidad propia del cerebro humano y el ámbito de la interpersonalidad, en el cual nacemos y maduramos como personas, siendo desde el primigenio contacto materno invitados a ser personas, a ser libres y dueños de nuestra vida. Es cierto que estos niveles de nuestra realidad no son objeto ni pueden ser demostrados por la metodología científica, pero no sólo es verdadero lo que resiste la evidencia empírica científica, y lo que está claro es que si no puede demostrarse la libertad, tampoco puede demostrarse el determinismo. En definitiva, aunque no podemos demostrar empíricamente la libertad, no podemos menos que afirmar con contundencia que sin libertad no se explica nada de la realidad humana.

\section{Referencias}

- Allman, J. M. (2003). El cerebro en evolución. Barcelona, España: Ariel.

- Arana, J. (2005). Adulterar la libertad: Dennett. En Los filósofos y la libertad, cap. 9. Madrid, España: Editorial Síntesis.

- Bechtel, W. (1991). Filosofía de la mente, cap. 2. Madrid, Tecnos.

- Beorlegui, C. (2015). El emergentismo humanista de Javier Monserrat. Pensamiento, vol. 71 ( $\mathrm{n}^{\circ}$ 269, Serie especial $\left.N^{\circ} 7\right)$, pp. 1165-1200 y 1190-1195.

. (2011). La singularidad de la especie humana. De la hominización a la humanización. Bilbao: Universidad de Deusto.

- (2009). Emergentismo. Pensamiento, 65 ( $N^{\circ}$ 246, Serie Especial, No 3), pp. 881-914.

- _ (Enero-marzo de 2007). Filosofía de la mente. Visión panorámica y situación actual. Realidad (N 111, UCA, San Salvador), pp.121-160.

• . (2006). Los emergentismos sistémicos: un modelo fructífero para el problema mente-cuerpo. Pensamiento, 62 ( $N^{\circ} 234$ ), pp. 391-439.

- Byrne, R. W. \& Whiten, A. (1988). Machiavellian Inteligence: Social Expertise and the Evolution of Intellect in Monkeys, Apes, and Humans. Oxford: Oxford University Press.

- Call, J. \& Tomasello, M. (2008). Does the Chimpanzees Have a Therory of Mind? 30 Years Later. Trends in Cognition Sciences, 12 (5), pp. 187-192, 191.

- Chalmers, D. (1999). La mente consciente. En busca de una teoría fundamental. Barcelona, España: Gedisa.

- Churchland, P. M. (1999). Materia y conciencia. Introducción contemporánea a la filosofía de la mente. Barcelona, España: Gedisa. 
- Cortina, A. (2011). Neuroética y neuropolítica. Sugerencias para la educación moral. Madrid, España: Tecnos, pp. 177-192.

- Crick, Fr. (1994). La búsqueda científica del alma. Una revolucionaria hipótesis para el siglo XXI. Madrid, España: Debate.

- Damasio, A. (2011). El cerebro hizo al hombre. Barcelona, España: Destino.

- _ (2003). Looking for Spinoza. Nueva York, USA: Harcourt Brace and Co. (Traducido al español: En busca de Spinoza. Neurobiología de la emoción y de los sentimientos (2005). Barcelona, España: Crítica. Brace and Co. . (1999). The feeling of what happens. Nueva York, USA: Harcourt . (1994). Descartes' Error. Emotion, Reason and the Human Brain. Nueva York, USA: G.P. Putnam's Son. (Traducido al español: El error de Descartes. La emoción, la razón y el cerebro humano (1996). Barcelona, España: Crítica).

- Davidson, D. (1980). Essays on actions and events. New York, USA: Oxford University Press.

- De Waal, F. (2007). Primates y filósofos. La evolución de la moral del simio al hombre, Barcelona, España: Paidós.

. (1997). Bien Natural. Los orígenes del bien y del mal en los humanos y otros animales. Barcelona, España: Herder. . (1993). La política de los chimpancés. Madrid, España: Alianza.

- Dennett, D. (2004). La evolución de la libertad. Barcelona, España: Paidós, pp. 331-332. . (1996). Contenido y conciencia. Barcelona, España: Gedisa, p. 248.

- Diéguez, A. (2009). Sistemas cognitivos y representaciones mentales desde la perspectiva evolucionista. En Martínez Freire, P. F., Representaciones, Contrastes (Málaga), (Suplemento 14).

- Eccles, J. (1995). Evolution of the Brain. Creation of the Brain. London: Routledge. . (1986). La psique humana. Madrid, España: Tecnos.

- Eccles, J.C. y Zeier, H. (1985). El cerebro y la mente. Barcelona, España: Herder.

- Edelman, G. M. \& Tononi, G. (2000). A universe of consciousness. How matter becomes imagination. New York, USA: Basic Books. (Traducido al español: El universo de la conciencia. Cómo la materia se convierte en imaginación. (2002). Barcelona, España: Crítica). 
- Edelman, G. M. (1992). Bright Air, Brilliant Fire: On The Matter of the Mind. New York, USA: Basic Books. . (1989). The Remembered Present: A Biological Theory of Consciousness. New York, España: Basic Books.

- Frankfurti, H. G. (2006). La importancia de lo que nos preocupa. Ensayos filosóficos. (La libertad de la voluntad y el concepto de persona). Buenos Aires, Argentina: Katz Editores, pp. 25 y ss.

- García Carpintero, M. (1995). El funcionalismo. En Broncano, F. (ed.), La mente humana. Madrid, España: Trotta, pp. 43-76.

- Gardner, H. (2000). La nueva ciencia de la mente. Historia de la revolución cognitiva. Barcelona, Paidós, ( $2^{\mathrm{a}}$ ed.), pp. 116 y ss. pp. 76 y ss. . (1988). La ciencia. Lo bueno, lo malo y lo falso. Madrid, España: Alianza, pp. 605-633. - (1987). La nueva filosofía de la mente. Historia de la revolución cognitiva. Barcelona, España: Paidós.

- Gleick, J. (2012). Caos. La creación de una ciencia. Barcelona, España: Crítica.

- Gómez, A. (2002). Acción, razones y valores en la filosofía de Georg Henrik von Wright. Introducción a von Wright, G. H. Sobre la libertad humana. Barcelona, España: Paidós.

- Gómez, J. C. (2005). Humpty-Dumpty y el eslabón perdido: Sobre la evolución del lenguaje a partir de la evolución de los primates. En Guillén-Salazar, F. (ed.), Existo, luego pienso: Los primates y la evolución de la inteligencia humana. Madrid, España: Ateles, pp. 147-169.

- González Álvarez, J. (2010). Breve historia del cerebro. Barcelona, España: Crítica.

- González Sanz, G. (2007). Entre libertad y determinismo. Genes, cerebro y ambiente en la conducta humana. Madrid, España: Cristiandad, pp. 126-129.

- Gutiérrez, G. (2000). Ética y decisión racional. Madrid, España: Editorial Síntesis. Olson, M. (1992). La Lógica de la Acción Colectiva. Bienes Públicos y la Teoría de Grupos. México: Grupo Noriega Editores.

- Häffner G. (1986. En Antropología filosófica. Barcelona, España: Herder, pp. 162 y ss.

- Hameroff, S. R. \& Watt, R. C. (1983). Do anesthetics act by altering electron mobility? Anesth Analg (62), pp. 936-940.

- (1982). Information processing in microtubules. J. Theor Biol, (98), pp. 549-561. 
- Hare, B., Call, J. \& Tomasello, M. (2001). Do Chimpanzees Know What Conspecifics Know? Animal Behaviour, (61), pp. 139-151.

- Hart, S. (1997). El lenguaje de los animales. Barcelona, España: Omega.

- Hierro Pescador, J. (2005). Filosofía de la mente y de la Ciencia Cognitiva. Madrid, España: Akal.

- Kaminski, J., Call, J., Tomasello, M. (2008). Chimpanzees Know What Other Know, but not What They Bilieve. Cognition (109), pp. 224-234.

- Kenneally, Chr. (2008). La primera palabra. La búsqueda de los orígenes del lenguaje, Cap. 2. Sue Savage-Rumbaugh. Madrid, España: Alianza, pp. 63-76

- Lewis, M. D. (2005). Bridging emotion therory and neurobiology through dynamic systems modeling. Behavioral and Brain Sciences (28), pp.169-194.

- Libet, B., y otros. (1983). Times of conscious intention to act in relation to onset of cerebral activity. Brain (106), pp. 623-642.

- Lorenz, K. (1980). La otra cara del espejo. Barcelona, España: Plaza y Janés.

- Maes, P. (1994). Modeling Adaptative Autonomous Systems. Artificial Life (1), pp. 135-162.

- Martí, E. (1997). Construir una mente. Barcelona, España: Paidós.

- Martínez Freire, P. F. (1995). La nueva filosofía de la mente, Barcelona, España: Gedisa.

- Melden. (1968). Action. En N. S. Care, y Ch. Landesman, (Eds.), Readings in the theory of action. Bloomington-London: Indiana University Press.

- Monserrat, J. (2012). El problema del soporte físico de la sensibilidadconciencia. En Rodríguez Valls, Fco. (ed.), La inteligencia de la naturaleza. Del relojero ciego al ajuste fino del universo. Madrid, España: Biblioteca Nueva, pp. 101-118.

- (2000). Penrose y el enigma cuántico de la conciencia. Pensamiento 56, ( $\left.\mathrm{N}^{\circ} 215\right)$, pp. 177-208.

- (1999). Penrose y la mente computacional. Pensamiento 55, $\left(\mathrm{N}^{\circ}\right.$ 212), pp. 177-216.

- Moreno, A. (2009). El origen de la volición. En Martínez Freire, P. F., Representaciones, Málaga. Contrastes, (Suplemento 14), pp. 225-240, 225.

- Moya, C. J. (2004). Filosofía de la mente. Valencia, España: PUV.

- Noble D. (2008). La música de la vida. Más allá del genoma humano. Madrid, España: Akal. 
- O'Connell, S., Dunbar, R. I. M. (2003). A test for comprehension of false belief in chimpanzees. Evolution and Cognition, (9), pp. 131-140.

- Ortega y Gasset, J. (1983). Sobre la expresión, fenómeno cósmico. El Espectador (vol. VII, agosto 1925). Obras Completas 12 vols. Madrid, España: Alianza/ Revista de Occidente vol. II, pp. 577-594. . (1957). El hombre y la gente. Madrid, España: Espasa-Calpe.

- Parsons, T. \& Shils, E. A. (Eds.). (1962). Toward a general theory of action. New York, USA: Harper Torchbook.

- Penrose, R. (1996). Las sombras de la mente. Hacia una comprensión científica de la mente. Barcelona, España: Crítica. Mondadori.

(1991). La nueva mente del emperador. Madrid, España:

- Penrose, R., Shimony, A. y Hawking, S. (1999). Lo grande, lo pequeño y la mente humana. Madrid, España: Cambridge University Press.

- Petit, P. (2007). Neuroscience and Agent-Control. En Spurret, D., y otros (eds.), Distributed Cognition and the Will: Individual Volition and Social Context. Cambridge: (MA), MIT Press, pp. 77-91.

- Popper, K. R. (1984). El universo abierto. Un argumento en favor del indeterminismo. Madrid, España: Tecnos.

- Popper, K. R. y Eccles, J. C. (1980). El yo y su cerebro. Barcelona, España: Labor.

- Premack, D. \& Woodruf, G. (1978). Does the Chimpanzee Have a Theory of Mind? Behavioral and Brain Sciences, (N¹), pp. 515-525.

- Priest, S. (1994). Teorías y filosofías de la mente, parte II. Madrid, España: Cátedra, pp. 55 y ss.

- Prigogine, I. \& Stengers, I. (1983a). La nueva alianza. Metamorfosis de la ciencia. Madrid, España: Alianza. . (1983b). ¿Tan sólo una ilusión? Barcelona, España: Tusquets.

- Rabosi, E. (1995). La tesis de la identidad mente-cuerpo. En Broncano, F. (ed.), La mente humana. Madrid, España: Trotta, pp. 17-42.

- Ricoeur, P. (1996). Sí mismo como otro. Madrid, España: Siglo XXI.

- _ _ (1988). El discurso de la acción. Madrid, España: Cátedra.

- Rubia, F. J. (2007). El cerebro nos engaña. Madrid, España: Temas de Hoy.

- Ryle, G. (1967). El concepto de la mental. Buenos Aires, Argentina: Paidós. 
- Sanguineti, J. J. (2007). Filosofía de la mente. Un enfoque ontológico y antropológico. Madrid, España: Edic. Palabra.

- Scott, D. (2004). Intelligence, the brain, and free will. Recuperado de The Visual Writer.com

- Searle, J. (2005). Libertad y neurobiología. Reflexiones sobre el libre albedrío, el lenguaje y el poder político. Barcelona, España: Paidós.

Nobel, p. 16.

. (2000a). Razones para actuar. Una teoría del libre albedrío. Oviedo:

. (2000b). El misterio de la conciencia. Barcelona, España: Paidós.

. (1995). Mentes y cerebros sin programas. En Rabossi, E. (Comp.),

Filosofía de la mente y ciencia cognitiva. Barcelona, España: Paidós, pp. 413-443.

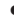

(1985). Mentes, cerebros y ciencia. Madrid, España: Cátedra. . (1983). Intentionality. Cambridge/London: C.U.P.

- Smith, L. (2011). Caos: una breve introducción. Madrid, España: Alianza, 2011.

- Smithers, T. (1997). Autonomy in Robots and Others Agents. Brain and Cognition (34), pp. 88-106.

- Squires, E. (1994). The Mystery of the Quantum World. Bristol: A. Hilger Ltd.

- Strawson, G. (2008). Intencionalidad real. (Por qué la intencionalidad entraña conciencia). Teorema, XXVII (3), pp. 35-69. . (1994). Mental Reality. Cambridge (MA): MIT Press.

- Thom, R. (1987). Estabilidad estructural y morfogénesis. Ensayo de una teoría general de los modelos, Barcelona, España: Gedisa.

- Tomasello, M. (2013. Los orígenes de la comunicación humana, Buenos Aires, Argentina: Katz Editores.

Editores.

. (2010). ¿Por qué cooperamos?, Buenos Aires, Argentina: Katz

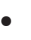

(2007). Los orígenes culturales de la cognición humana. Buenos Aires/Madrid: Amorrortu.

- Von Wright, G. H. (1970). Norma y acción. Madrid, España: Tecnos.
- . (1979a). Explicación y comprensión. Madrid, España: Alianza.
Tecnos. . (1979b). Norma y acción. Una investigación lógica. Madrid, España:




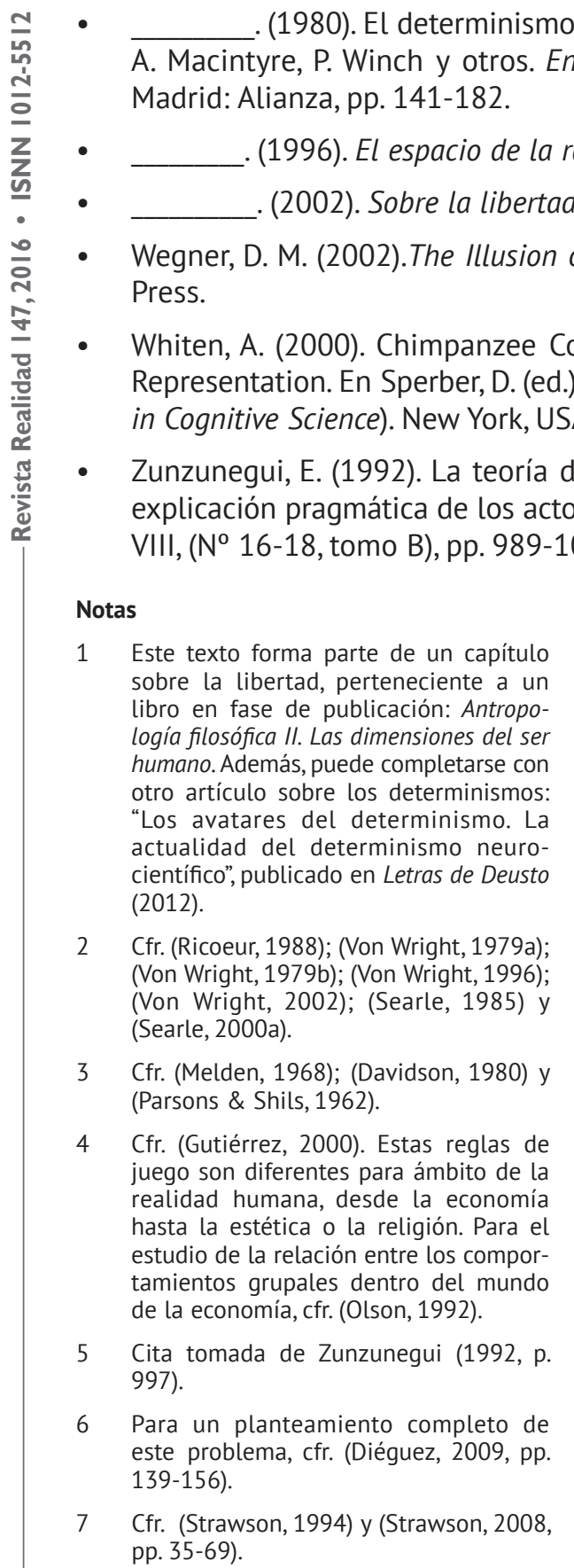

8 Cfr. (Premack, \& Woodruf, 1978, pp. 515-525); (Hart, 1997); (Gardner, 1988, pp. 605-633) y (Kenneally, 2008, pp. 63-76).

9 Cfr. (Martí, 1997). Construir una mente, este libro recoge en su segunda parte las teorías de Piaget e Inhelder como la mente infantil, las teorías de Premack y Woodruff sobre la posibilidad de que los chimpancés tengan teoría de la mente, y los planteamientos de Perner, Leekam y Wimmer, sobre las creencias de los niños pequeños.

10 Cfr. (Premack \& Woodruff, 1978); (Byrne \& Whiten, 1988); (De Waal, 1993); (De Waal, 1997) y (De Waal, 2007).

11 Cfr. (Hare, Call \& Tomasello, 2001, pp. 139-151). Es interesante hacer referencia a lo que dice J. Searle respecto a los chimpancés: pueden engañar, pero no pueden mentir, en su libro Razones para actuar. Una teoría del libre albedrío (Searle, 2000, p. 16). Esta diferencia se sitúa no tanto en el nivel de la capacidad mental sino en el ámbito de la ética y de la responsabilidad.

12 Cfr. (Whiten, 2000, pp. 139-167) y (Kaminski, Call y Tomasello, 2008, pp. 224-234).

13 Cita tomada de Diéguez, (2009, pp. 218-219). Tomasello ha ido 
progresivamente situándose en una clara postura de diferenciación cualitativa entre la mente animal y humana, cfr. (Tomasello, 2007); (Tomasello, 2010) y (Tomasello, 2013).

14 (Moreno, 2009, pp. 225-240, 225). Voy a seguir en este apartado las ideas de este artículo.

15 Cfr. (Edelman, 1992) y (Edelman \& Tononi, 2000).

16 Cfr. (Allman, 2003); (González Álvarez, 2010) y (Edelman \& Tononi, 2000).

17 Cfr. (Damasio, 1994); (Damasio, 1999); (Damasio, 2003) y (Lewis, 2005, pp.169-194).

18 Cfr. Monserrat, J. Artículo. En Pensamiento sobre las teorías de Damasio.

19 Cfr. (Crick, 1994); (Edelman, 1989); (Edelman \& Tononi, 2000); (Penrose, 1991); (Penrose, 1996); (Chalmers, 1999); (Searle, 2000b) y (Damasio, 2011).

20 Cfr. (Gardner, 2000, pp. 116 y ss).

21 Cfr. Churchland, 1999); (Martínez Freire, 1995); (Broncano, 1995); (Hierro Pescador, 2005) y (Moya, 2004); (Sanguineti, 2007); (Beorlegui, enero-marzo de 2007, pp.121-160).

22 Cfr. (Eccles, 1986); (Eccles, 1995); (Popper, y Eccles, 1980) y (Eccles y Zeier, 1985).

23 Cfr. (Beorlegui, 2006, pp. 391-439) y (Beorlegui, 2009, pp. 881-914).

24 Cfr. (Clayton, 2011, pp. 40 y ss).

25 Cfr. Sobre el conductismo lógico: (Priest, 1994, pp. 55 y ss); (Bechtel, 1991, Cap. 2); (Martínez Freire, 2009 , cap. $4^{\circ}$ y $5^{\circ}$ ) y (Gardner, 2000, pp. 76 y ss).

26 Cfr. (Clayton, 2011, p. 41) y (Arana, 2005, cap. 9).

27 La cursiva y las palabras entrecomilladas son del autor. Cfr. (Clayton, 2011, p. 42).

28 Cfr. (Clayton, 2011, p. 45).

29 Denis Noble en su libro: La música de la vida. Más allá del genoma humano (2008) -sobre todo en el cap. 9- estudia la conformación del cerebro como un teatro, o una orquesta sinfónica sin director pero, a diferencia de Dennett, no deduce de ello la no existencia del yo, sino precisamente lo contrario, desde una concepción sistémica y emergente de la evolución y del desarrollo y funcionamiento del cerebro.

30 Cfr. (Dennett, 2004, pp. 331-332); (Clayton, 2011, pp. 45-48) y (Frankfurti, 2006, pp. 25 y ss).

31 J. Searle ha escrito diversos trabajos sobre la libertad. El más completo es Razones para actuar. Una teoría del libre albedrío (2000a). Sigo sobre todo Libertad y neurobiología. Reflexiones sobre el libre albedrío, el lenguaje y el poder político (2005) que, como el mismo Searle señala, es un resumen del libro anterior.

32 La palabra intervalo es la traducción del inglés gap, que el traductor de la obra de Searle, Razones para actuar. Una teoría del libre albedrío (2000a), lo traduce por brecha. Cfr. Searle (2005, p. 14), donde hace una referencia explícita a la idea de intervalo/gap.

33 Razones para actuar (2000a). En ese libro se detiene más ampliamente Searle en explicar cómo se relacionan las razones y las acciones.

34 Cfr. (Beorlegui, 2006, pp. 391-439).

35 Sobre el compatibilismo, cfr. (Cortina, 2011, pp. 177-192) y (González Sanz, 2007, pp. 126-129).

36 Sobre la diferencia en este punto entre Searle y Penrose, cfr. (Beorlegui, 2015, pp. 1165-1200), sobre todo en las páginas 1190-1195.

37 Cfr. (Scott, 2004); (Squires, 1994) y (Popper, 1984).

38 Cfr. (Thom, 1987); (Prigogine \& Stengers, 1983a); (Prigogine \& Stengers, 1983b); (Gleick, 2012) y (Smith, 2011).

39 (Penrose, 1996) y (Penrose, Shimony y Hawking, 1999).

40 (Hameroff. \& Watt, 1982, pp. 549-561) y (Hameroff \& Watt, 1983. pp. 936-940.)

41 Cfr. (Searle, 2000b, cap. 4º); (Monserrat, 1999); (Monserrat, 2000) y (Monserrat, 2012). 
42 Cfr. (Searle, 2000b, cap. 4), (Searle, 2005, pp. 76 y ss).

43 Similar argumentación contra el determinismo (por suponer una contradicción) propone Häffner (1986, pp. 162 y ss).
44 Cfr. (Popper \& Eccles, 1980).

45 Cfr. (Ortega y Gasset, 1983, pp. 577-594) y (Ortega y Gasset, 1957, p. 118). 